\title{
Silver-Catalyzed Oxidation of Atropine Drug by Cerium(IV) in Aqueous Perchlorate Solutions: A Kinetics and Mechanistic Approach
}

\author{
Ahmed Fawzy $^{1,2,{ }^{*} \text {, Ishaq A. Zaafaray }}{ }^{1}$, Ismail I. Althagafi ${ }^{1}$, Hatem M. Altass ${ }^{1}$ \\ ${ }^{1}$ Chemistry Department, Faculty of Applied Science, Umm Al-Qura University, Makkah, Saudi Arabia \\ ${ }^{2}$ Chemistry Department, Faculty of Science, Assiut University, Assiut, Egypt \\ Email address: \\ afsaad13@yahoo.com (A. Fawzy), iazaafarany@uqu.edu.sa (I. A. Zaafarany), iithagafi@uqu.edu.sa (I. I. Althagafi), \\ hatem1401@hotmail.com (H. M. Altass) \\ ${ }^{*}$ Corresponding author
}

\section{To cite this article:}

Ahmed Fawzy, Ishaq A Zaafaray, Ismail I. Althagafi, Hatem M. Altass. Silver-Catalyzed Oxidation of Atropine Drug by Cerium(IV) in Aqueous Perchlorate Solutions: A Kinetics and Mechanistic Approach. Journal of Drug Design and Medicinal Chemistry.

Vol. 2, No. 5, 2016, pp. 51-59. doi: 10.11648/j.jddmc.20160205.12

Received: August 28, 2016; Accepted: October 12, 2016; Published: October 21, 2016

\begin{abstract}
The kinetics of oxidation of atropine drug (ATR) by cerium(IV) in aqueous perchlorate solutions in the presence of silver(I) catalyst has been studied spectrophotometrically at a constant ionic strength and temperature. The reaction showed first order dependence with respect to each [Ce(IV)] and [Ag(I)], and less than unit order kinetics with respect to [ATR]. The reaction exhibited negative fractional-first order kinetics with respect to $\left[\mathrm{H}^{+}\right]$. Increasing ionic strength and dielectric constant of the medium increased the reaction rate. In the present work, the kinetically active species of cerium(IV) was found to be $\mathrm{Ce}(\mathrm{OH})^{3+}$. Addition of $\mathrm{Ce}(\mathrm{III})$ product had no significant effect on the oxidation rate. The oxidation products of atropine were identified by spectral and chemical analyses as tropine, benzaldehyde, methanol and carbon dioxide. A plausible mechanistic scheme for the catalyzed oxidation was proposed. The activation parameters of the second order rate constant were calculated and the rate law associated with the reaction mechanism was derived.
\end{abstract}

Keywords: Atropine, Oxidation, Cerium(IV), Kinetics, Mechanism

\section{Introduction}

Atropine (ATR) or tropine alkaloid, is an anticholinergic drug which contains two cyclic structures (alicyclic nitrogencontaining alcohol tropine and aromatic tropic acid) joined by an ester linkage [1]. It occurs naturally in plants in the nightshade family including deadly nightshade, Jimson weed and mandrake [2]. It is a secondary metabolite of such plants and serves as a drug with a wide variety of effects. Atropine is considered as a core medicine in the World Health Organization (WHO), which is a list of minimum medical needs for a main health care system. It is a competitive antagonist for the muscarinic acetylcholine receptor. Furthermore, it is a specific antidote for the treatment of poisoning with various agents. Its degradation by microorganisms has been reported by several groups [3] and in the initial stage, the hydrolysis of the ester linkage to give two separate cyclic components takes place.

Cerium(IV) is a significant single electron oxidant in acid media [4-17]. The oxidizing potentialities of cerium(IV) in sulfuric acid medium were conclusively established $[10,11]$. In perchloric acid medium, the oxidant has rarely been employed $[15,16]$, probably due to presence of dimers and polymers of cerium(IV) in such medium [16]. However, the oxidation by cerium(IV) in perchloric acid solutions proceed much faster than those in sulfuric acid ones. Oxidations of various substrates by Ce (IV) are found to follow different mechanisms, depending on the acid medium used.

Transition metal ions have been widely used as homogeneous catalysts for oxidation of organic and inorganic substrates [18-20]. Kinetic investigations on the homogeneous catalyzed oxidation of organic compounds are 
considered to be a significant field of chemistry because of the role played by metals in biological systems.

Although some work on the oxidation of atropine by various oxidants has been performed [21-25], there is a lack of literature on the kinetics of oxidation of this drug by cerium(IV) in the absence or presence of a catalyst. This observation prompted us to investigate the title reaction. The objectives of the present study are to check the reactivity of atropine drug towards cerium(IV) in perchlorate medium, to understand the active species of the reactants in such medium, to check the catalytic activity of $\operatorname{Ag}(\mathrm{I})$ and finally to propose a plausible oxidation mechanism of such drug.

\section{Experimental}

\subsection{Materials}

All chemicals used in this work were of reagent grade and their solutions were prepared by dissolving the required amounts of the samples in doubly distilled water. The stock solution of atropine was prepared by dissolving the sample, atropine sulfate monohydrate $\left(\mathrm{C}_{17} \mathrm{H}_{23} \mathrm{NO}_{3}\right)_{2} . \mathrm{H}_{2} \mathrm{SO}_{4} . \quad \mathrm{H}_{2} \mathrm{O}$ (Aldrich), in doubly distilled water. A fresh solution of cerium(IV) was prepared by dissolving ceric ammonium sulfate (Sigma) in sulfuric acid, diluted with double distilled water and kept for overnight. The solution of cerium(IV) was stored in a dark glass bottle and was used after $24 \mathrm{~h}$ [26]. Cerium(III) solution was prepared by dissolving cerium(III) acetate (Sigma) in double distilled water.

\subsection{Kinetic Measurements}

All kinetic measurements were followed under pseudofirst order conditions in an excess of atropine over cerium(IV). The course of the reaction was monitored by following the decrease in absorbance of cerium(IV) as a function of time at $\lambda=315 \mathrm{~nm}$, its absorption maximum, whereas the other constituents of the reaction mixtures had no significant absorption at this wavelength as shown in figure 1. The absorbance measurements were made in a thermostatted Shimadzu UV-VIS-NIR-3600 double-beam spectrophotometer.

It was observed that the oxidation reaction did not proceed in the absence of silver(I) catalyst. The pseudo-first order rate constant values $\left(k_{\mathrm{C}}\right)$ were calculated using non-linear leastsquares fitting to the first order dependence of the absorbance versus time plots. The rate constants were the mean values of at least three kinetic measurements. The rate constants were reproducible to $3-4 \%$.

The spectral changes for the oxidation of atropine by cerium(IV) in perchlorate solution are shown in figure 1. The scanned spectra indicate gradual decay of $\mathrm{Ce}(\mathrm{IV})$ band at its absorption maximum with time as a result of its reduction to Ce(III).

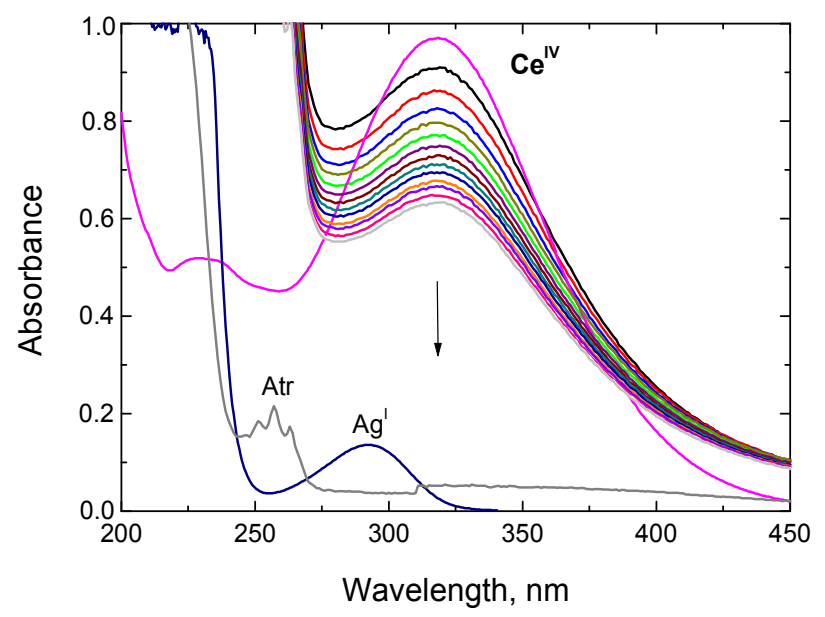

Figure 1. Spectral changes during the silver(I)-catalyzed oxidation of atropine by $\mathrm{Ce}(\mathrm{IV})$ in perchlorate solutions. $[\mathrm{ATR}]=5.0 \times 10^{-3},[\mathrm{Ce}(\mathrm{IV})]=$ $2.0 \times 10^{-4},\left[H^{+}\right]=0.5, I=1.0 \mathrm{~mol} \mathrm{dm^{-3 }}$ at $25^{\circ} \mathrm{C}$. Scan time intervals $=3 \mathrm{~min}$.

\section{Results and Discussion}

\subsection{Stoichiometry and Product Characterization}

Reaction mixtures containing various amounts of Ce(IV) and atropine at constant $\left[\mathrm{H}^{+}\right]$, ionic strength, $[\mathrm{Ag}(\mathrm{I})]$ and temperature were allowed to react for $24 \mathrm{~h}$ in closed vessels for completion of the oxidation reaction. The unconsumed [Ce(IV)] was determined spectrophotometrically at $315 \mathrm{~nm}$. The results indicated that two moles of $\mathrm{Ce}(\mathrm{IV})$ are consumed by one mole of atropine to yield the oxidation products as shown in the following equation,

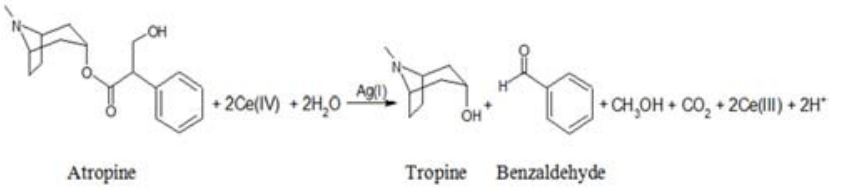

The above stoichiometric equation is consistent with the results of product identification. Tropine and benzaldehyde as the reaction products were identified by spectral analysis as described elsewhere [27-29]. Tropine was also identified by its hydrazone derivative [27]. Methyl alcohol was confirmed by sodium test [27] and carbon dioxide was detected by lime water.

\subsection{Reaction Orders with Respect to the Reactants}

The reaction orders with respect to the reactants were determined from the slopes of $\log k_{\mathrm{C}}$ versus $\log$ (concentration) plots by varying the concentrations of atropine substrate, perchloric acid and silver(I) catalyst, in turn, while keeping other conditions constant.

The oxidant Ce(IV) was varied in the range of $0.5 \times 10^{-4}$ to $5.0 \times 10^{-4} \mathrm{~mol} \mathrm{dm}^{-3}$ keeping other variables constant. It has been observed that the increase in the oxidant concentration does not change the oxidation rate of atropine (table 1). This indicated that the oxidation rate is independent of oxidant concentration and the order of reaction with respect to the oxidant is confirmed to be one. 
The observed rate constant was determined at different initial concentrations of the reductant atropine while other variables were kept constant. It was found that increasing atropine concentration increases the oxidation rate as listed in table 1 . A plot of $\log k_{\mathrm{C}}$ versus $\log$ [ATR] at constant $\mathrm{pH}$ was found to be linear with an intercept of 0.84 (figure 2) confirming the less than unit order dependence on [ATR].

The effect of hydrogen ion concentration on the oxidation rate was studied by varying the perchloric acid concentration in the range of $(0.1-1.0) \mathrm{mol} \mathrm{dm}^{-3}$ and keeping the concentrations of all other reactants constant. It was observed that the oxidation rate decreases with increasing $\left[\mathrm{H}^{+}\right]$(table 1). A plot of $\log k_{\mathrm{obs}}$ versus $\log \left[\mathrm{H}^{+}\right]$was linear with a negative slope of -0.48 as shown in figure 3 confirming the negative fractional-first order dependence in $\left[\mathrm{H}^{+}\right]$.

The reaction rate was measured with various $[\mathrm{Ag}(\mathrm{I})],(2.0$ - 12.0) $\times 10^{-5} \mathrm{~mol} \mathrm{dm}^{-3}$ at constant other variables. The reaction rate increased directly with increase in $[\mathrm{Ag}(\mathrm{I})]$ (table $1)$. The order with respect to $[\mathrm{Ag}(\mathrm{I})]$ was found to be unity, as found from the plot of $\log k_{\mathrm{C}}$ versus $\log [\operatorname{Ag}(\mathrm{I})]$ (figure 4).

\subsection{Effect of Ionic Strength and Dielectric Constant}

The effect of ionic strength on the oxidation rate was studied by varying the ionic strength in the range $1.0-3.0$ mol $\mathrm{dm}^{-3}$ using sodium perchlorate as an inert electrolyte keeping the concentrations of all other reactants constant. The results indicated that increasing ionic strength increases the reaction rate as listed in table 1, and the Debye-Huckel plot was found to be linear with a positive intercept as shown in figure 5 .

The effect dielectric constant $(D)$ was also studied by varying the acetic acid - water content in the reaction mixture with all other conditions being kept constant. The data clearly revealed that the rate constant $k_{\mathrm{C}}$ decreases with the decrease in dielectric constant of the solvent mixture; i.e. increase in acetic acid content. The plot of $\log k_{\mathrm{C}}$ versus $1 / D$ was linear with a negative slope as shown in figure 6 .

Table 1. Effect of variation of [Ce(IV)], [ATR], $\left[H^{+}\right],[A g(I)]$ and ionic strength (I) on the pseudo-first order rate constant values, $k_{C}$, in the silver(I)-catalyzed oxidation of atropine by $\mathrm{Ce}(\mathrm{IV})$ in perchlorate solutions at $25^{\circ} \mathrm{C}$.

\begin{tabular}{|c|c|c|c|c|c|}
\hline $\begin{array}{l}10^{4}[\mathrm{Ce}(\mathrm{IV})] \\
\left(\mathrm{mol} \mathrm{dm}^{-3}\right)\end{array}$ & $\begin{array}{l}10^{3} \text { [ATR] } \\
\left(\mathrm{mol} \mathrm{dm}^{-3}\right)\end{array}$ & $\begin{array}{l}{\left[\mathrm{H}^{+}\right]} \\
\left(\mathrm{mol} \mathrm{dm}^{-3}\right)\end{array}$ & $\begin{array}{l}{[\operatorname{Ag}(\mathrm{I})]} \\
\left(\mathrm{mol} \mathrm{dm} \mathbf{d m}^{-3}\right)\end{array}$ & $\begin{array}{l}I \\
\left(\mathrm{~mol} \mathrm{dm}^{-3}\right)\end{array}$ & $\begin{array}{l}10^{3} k_{\mathrm{C}} \\
\left(\mathrm{s}^{-1}\right)\end{array}$ \\
\hline 0.5 & 5.0 & 0.5 & 6.0 & 1.0 & 17.9 \\
\hline 1.0 & 5.0 & 0.5 & 6.0 & 1.0 & 17.4 \\
\hline 2.0 & 5.0 & 0.5 & 6.0 & 1.0 & 18.2 \\
\hline 3.0 & 5.0 & 0.5 & 6.0 & 1.0 & 19.1 \\
\hline 4.0 & 5.0 & 0.5 & 6.0 & 1.0 & 18.7 \\
\hline 2.0 & 1.0 & 0.5 & 6.0 & 1.0 & 5.1 \\
\hline 2.0 & 3.0 & 0.5 & 6.0 & 1.0 & 12.3 \\
\hline 2.0 & 5.0 & 0.5 & 6.0 & 1.0 & 18.2 \\
\hline 2.0 & 7.0 & 0.5 & 6.0 & 1.0 & 24.1 \\
\hline 2.0 & 9.0 & 0.5 & 6.0 & 1.0 & 31.4 \\
\hline 2.0 & 11.0 & 0.5 & 6.0 & 1.0 & 37.7 \\
\hline 2.0 & 5.0 & 0.3 & 6.0 & 1.0 & 23.4 \\
\hline 2.0 & 5.0 & 0.5 & 6.0 & 1.0 & 18.2 \\
\hline 2.0 & 5.0 & 0.7 & 6.0 & 1.0 & 15.0 \\
\hline 2.0 & 5.0 & 0.9 & 6.0 & 1.0 & 13.1 \\
\hline 2.0 & 5.0 & 1.0 & 6.0 & 1.0 & 11.9 \\
\hline 2.0 & 5.0 & 0.5 & 2.0 & 1.0 & 5.8 \\
\hline 2.0 & 5.0 & 0.5 & 4.0 & 1.0 & 11.7 \\
\hline 2.0 & 5.0 & 0.5 & 6.0 & 1.0 & 18.2 \\
\hline 2.0 & 5.0 & 0.5 & 8.0 & 1.0 & 23.8 \\
\hline 2.0 & 5.0 & 0.5 & 10.0 & 1.0 & 30.3 \\
\hline 2.0 & 5.0 & 0.5 & 12.0 & 1.0 & 35.9 \\
\hline 2.0 & 5.0 & 0.5 & 6.0 & 1.0 & 18.2 \\
\hline 2.0 & 5.0 & 0.5 & 6.0 & 2.2 & 27.9 \\
\hline 2.0 & 5.0 & 0.5 & 6.0 & 2.6 & 31.1 \\
\hline 2.0 & 5.0 & 0.5 & 6.0 & 3.0 & 33.8 \\
\hline
\end{tabular}

Experimental error $\pm 3 \%$. 


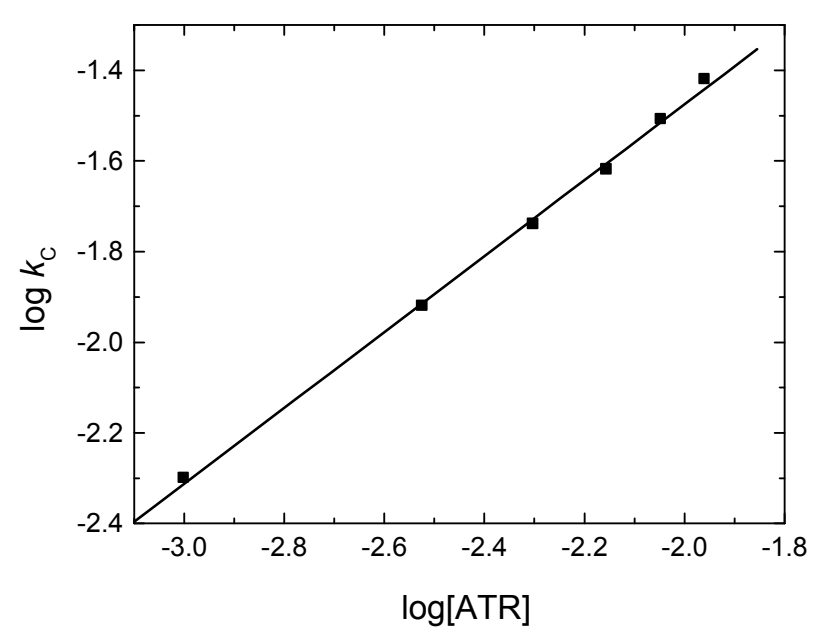

Figure 2. A plot of $\log k_{C}$ versus log [ATR] in the silver(I)-catalyzed oxidation of atropine by $\mathrm{Ce}(\mathrm{IV})$ in perchlorate solutions. $[\mathrm{Ce}(\mathrm{IV})]=2.0 \mathrm{x}$ $10^{-4},\left[H^{+}\right]=0.5,[\mathrm{Ag}(\mathrm{I})]=6.0 \times 10^{-5}$ and $I=1.0 \mathrm{~mol} \mathrm{dm} \mathrm{m}^{-3}$ at $25^{\circ} \mathrm{C}$.

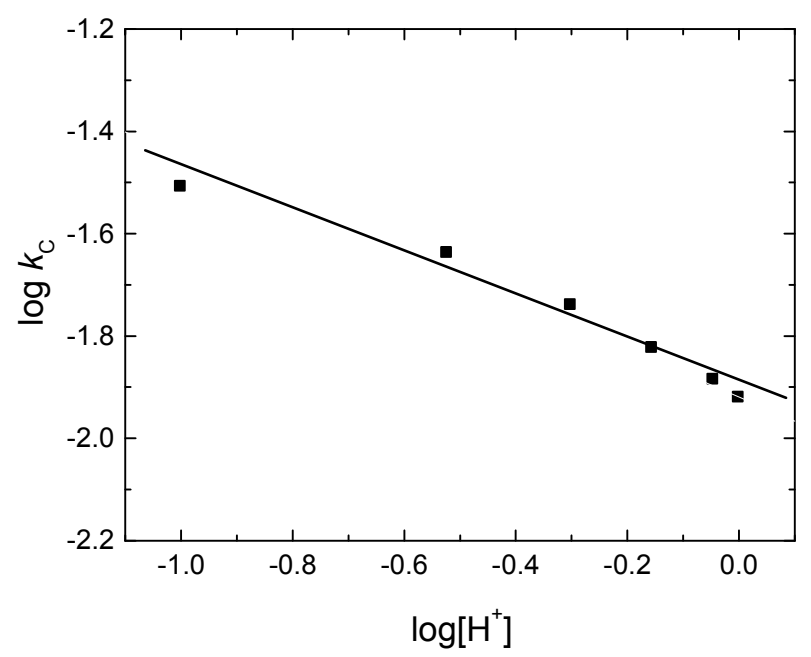

Figure 3. A plot of $\log k_{C}$ versus $\log \left[\mathrm{H}^{+}\right]$in the silver(I)-catalyzed oxidation of atropine by $\mathrm{Ce}(\mathrm{IV})$ in perchlorate solutions. $[\mathrm{ATR}]=5.0 \times 10^{-3},[\mathrm{Ce}(\mathrm{IV})]$ $=2.0 \times 10^{-4},[\mathrm{Ag}(\mathrm{I})]=6.0 \times 10^{-5}$ and $\mathrm{I}=1.0 \mathrm{~mol} \mathrm{dm^{-3 }}$ at $25^{\circ} \mathrm{C}$.

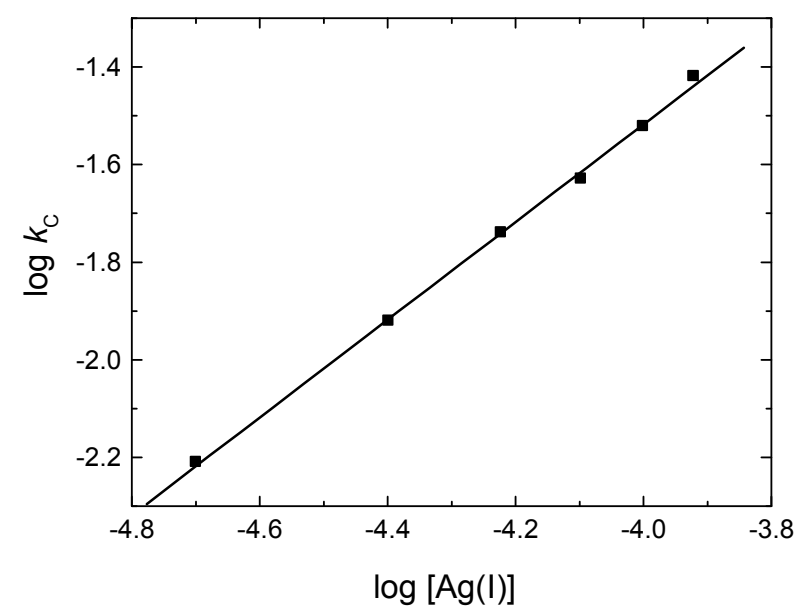

Figure 4. A plot of $\log k_{C}$ versus $\log [A g(I)]$ in the silver(I)-catalyzed oxidation of atropine by $\mathrm{Ce}(\mathrm{IV})$ in perchlorate solutions. $[\mathrm{ATR}]=5.0 \times 10^{-3}$, $[\mathrm{Ce}(I \mathrm{~V})]=2.0 \times 10^{-4},\left[\mathrm{H}^{+}\right]=0.5$ and $I=1.0 \mathrm{~mol} \mathrm{dm}^{-3}$ at $25^{\circ} \mathrm{C}$.

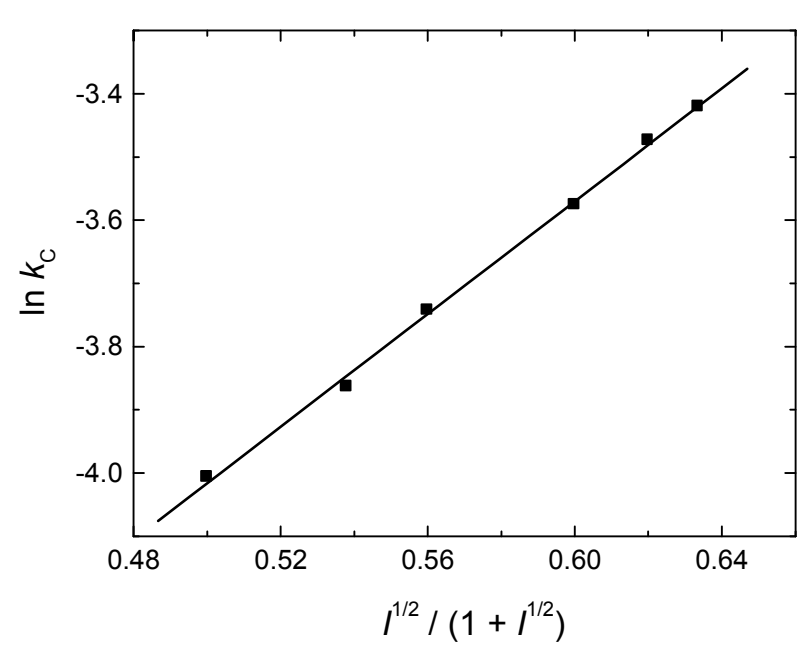

Figure 5. Deby-Huckel plot in the silver(I)-catalyzed oxidation of atropine by $\mathrm{Ce}(\mathrm{IV})$ in perchlorate solutions. $[\mathrm{ATR}]=5.0 \times 10^{-3}$, $[\mathrm{Ce}(\mathrm{IV})]=2.0 \times 10^{-4}$, $\left[\mathrm{H}^{+}\right]=0.5$ and $[\mathrm{Ag}(\mathrm{I})]=6.0 \times 10^{-5} \mathrm{~mol} \mathrm{dm}{ }^{-3}$ at $25^{\circ} \mathrm{C}$.

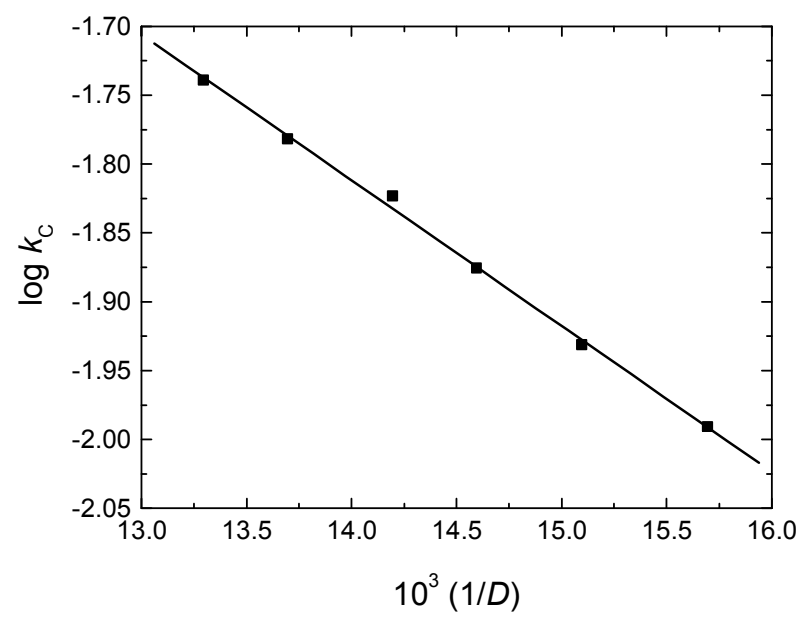

Figure 6. A plot of $\log k_{C}$ versus $1 / D$ in the silver(I)-catalyzed oxidation of atropine by $\mathrm{Ce}(I V)$ in perchlorate solutions. $[A T R]=5.0 \times 10^{-3},[\mathrm{Ce}(I V)]=$ $2.0 \times 10^{-4},\left[\mathrm{H}^{+}\right]=0.5$ and $I=1.0 \mathrm{~mol} \mathrm{dm} \mathrm{m}^{-3}$ at $25^{\circ} \mathrm{C}$.

\subsection{Effect of Initially Added Product}

The effect of added cerium(III) product was studied in the concentration range $0.5 \times 10^{-4}$ to $6.0 \times 10^{-4} \mathrm{~mol} \mathrm{dm}^{-3}$ at fixed concentrations of the oxidant, reductant and acid. It was found that $\mathrm{Ce}(\mathrm{III})$ has no significant effect on the oxidation rate of atropine.

\subsection{Effect of Temperature}

The oxidation rate was performed at five different temperatures in the range of $288-308 \mathrm{~K}$, at constant concentrations of the reactants and other conditions being constant. The activation parameters of the second order rate constant $\left(k_{1}\right)$ are calculated using Arrhenius and Eyring plots and are listed in table 2. 
Table 2. Activation parameters of the second order rate constants $k_{1}$ in the silver(I)-catalyzed oxidation of atropine by $\mathrm{Ce}(\mathrm{IV})$ in perchlorate solutions. $[A T R]=5.0 \times 10^{-3},[\mathrm{Ce}(I V)]=2.0 \times 10^{-4},\left[\mathrm{H}^{+}\right]=0.5$ and $I=1.0 \mathrm{~mol} \mathrm{dm}$.

\begin{tabular}{|c|c|c|c|}
\hline $\begin{array}{l}\Delta S^{\ddagger} \\
\mathbf{J} \mathbf{~ m o l}^{-1} \mathbf{K}^{-1}\end{array}$ & $\begin{array}{l}\Delta \boldsymbol{H}^{\mp} \\
\mathbf{k J} \mathbf{~ m o l}^{-1}\end{array}$ & $\begin{array}{l}\Delta G^{\ddagger}{ }_{298} \\
\mathrm{~kJ} \mathrm{~mol}^{-1}\end{array}$ & $\begin{array}{l}E_{\mathrm{a}}{ }^{\neq} \\
\mathrm{kJ} \mathrm{mol}^{-1}\end{array}$ \\
\hline-114.51 & 41.88 & 76.00 & 43.15 \\
\hline
\end{tabular}

\subsection{Test for Free Radical Intermediates}

The involvement of free radicals in the reaction was examined by polymerization test. The reaction mixture to which a known quantity of acrylonitrile scavenger has been added initially was kept in inert atmosphere for $6 \mathrm{~h}$. Upon diluting the reaction mixture with methanol, white precipitate has been formed, suggesting generation of free radical in the reaction. When the experiment was repeated in the absence of atropine under similar conditions, the test was negative. This indicates that the reaction was routed through free radical path.

\subsection{Reaction Mechanism}

It has been reported [30-32] that active species of cerium(IV) in perchloriate solutions were found to be either free monomeric species $\mathrm{Ce}^{4+}$, its hydrolyzed forms, $\mathrm{Ce}(\mathrm{OH})^{3+}, \mathrm{Ce}(\mathrm{OH})_{2}{ }^{2+}$ or partially dimeric species $(\mathrm{Ce}-\mathrm{O}-$ $\mathrm{Ce})^{6+}$ and $(\mathrm{HOCe}-\mathrm{O}-\mathrm{CeOH})^{4+}$. However, spectrophotometric studies showed [33] that the hydrated form, $\mathrm{Ce}^{4+}$, is the

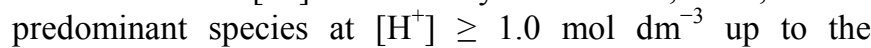
concentration of $1.5 \times 10^{-3} \mathrm{~mol} \mathrm{dm}^{-3}$ of cerium(IV), whereas the hydrolyzed forms and dimers are the more predominant at $\left[\mathrm{H}^{+}\right]<0.8 \mathrm{~mol} \mathrm{dm}^{-3}$. Therefore, under our experimental conditions of low $\left[\mathrm{H}^{+}\right]$and deceasing reaction rate with increasing $\left[\mathrm{H}^{+}\right], \mathrm{Ce}(\mathrm{OH})^{3+}$ may be regarded as the kinetically active form of cerium(IV) according to Eq. (1) in scheme 1.

The reaction between atropine and $\mathrm{Ce}(\mathrm{IV})$ in perchlorate solutions have a stoichiometry of 1:2, ATR: Ce(IV). The reaction exhibited first order dependence with respect to $[\mathrm{Ce}(\mathrm{IV})]$ and $[\mathrm{Ag}(\mathrm{I})]$, less than unit order with respect to [ATR] and negative fractional order in $\left[\mathrm{H}^{+}\right]$. The rate is not considerably affected by $\mathrm{Ce}$ (III) suggesting that the ratedetermining step should be irreversible as is generally the case for one electron oxidants [34] and the oxidation takes place throughout generation of free radicals as obtained experimentally. Also, increasing ionic strength and dielectric constant of the reaction medium increased the oxidation rate suggesting that the reaction occurs between two similarly charged ions $[35,36]$.

Owing to the experimental results, a plausible reaction mechanism has been proposed for which all the observed orders in each constituent may be well accommodated. The less than unit order with respect to atropine concentration suggests formation of an intermediate complex $\left(\mathrm{C}_{1}\right)$ between atropine and silver(I) catalyst prior to reaction with the oxidant. Complex formation was also proved kinetically by the non-zero intercept of the plot of $[\mathrm{Ag}(\mathrm{I})] / k_{\mathrm{C}}$ versus 1/[ATR] (figure 7a) in favor of possible formation of an intermediate complex between the oxidant and substrate [37]. Such complex reacts in a slow step with the active species of the oxidant, $\mathrm{Ce}(\mathrm{OH})^{3+}$, resulting in the formation of a free radical intermediate and one of the final product tropine derived from atropine sulfate, byproduct $\mathrm{CO}_{2}$ and $\mathrm{Ce}$ (III) ion with regeneration of the catalyst. The free radical species further reacts with another mole of the oxidant in a fast step to form the final oxidation products, benzaldehyde and methyl alcohol as illustrated in mechanistic scheme 1 .

$$
\mathrm{Ce}^{4+}+\mathrm{H}_{2} \mathrm{O} \stackrel{\mathrm{KOH}_{2}}{\rightleftharpoons} \mathrm{Ce}(\mathrm{OH})^{3+}+\mathrm{H}^{+}
$$

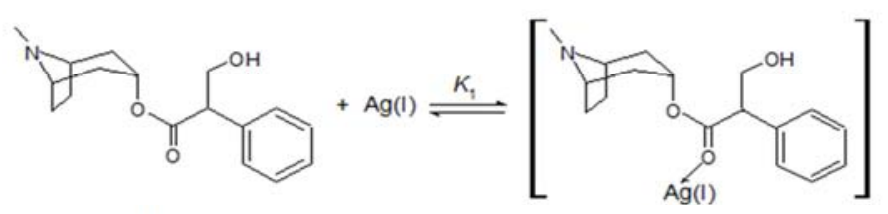

Atropine

$\left(C_{1}\right)$

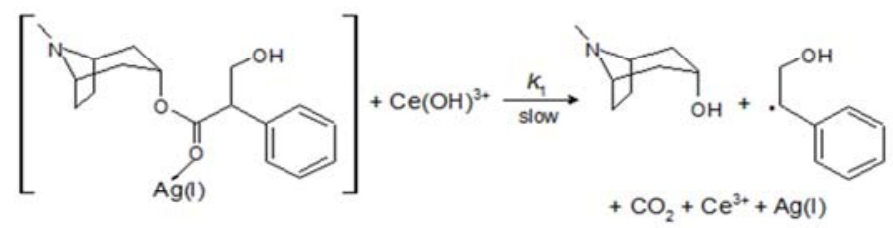

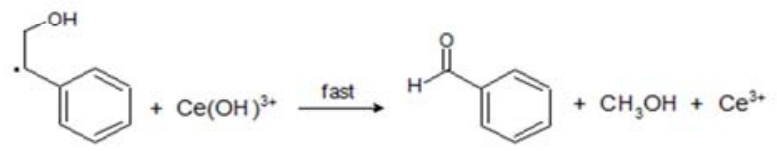


An alternative oxidation mechanism for metal ioncatalyzed oxidation was proposed earlier $[11,16,17]$. It involves formation of an intermediate complex $\left(\mathrm{C}_{1}\right)$ between the metal ion catalyst, $\operatorname{Ag}(\mathrm{I})$, and the substrate, ATR, that on further interaction with the oxidant, $\mathrm{Ce}(\mathrm{IV})$, in the ratedetermining step yields another complex $\left(\mathrm{C}_{2}\right)$ with higher valence metal ion, $\mathrm{Ag}(\mathrm{II})$, and $\mathrm{Ce}(\mathrm{III})$ ion. Such complex rapidly decomposes to an intermediate radical with regeneration of the catalyst $\operatorname{Ag}(\mathrm{I})$, followed by subsequent fast steps to yield the final oxidation products as illustrated in scheme 2.

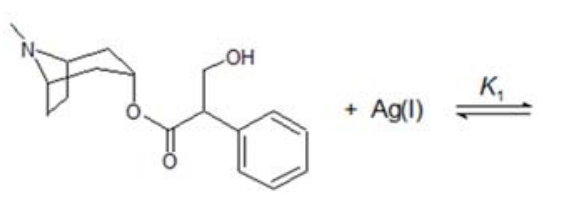<smiles>CN1C2CCCC1CC(OC(=O)C(CO)c1ccccc1)C2</smiles>

$\left(C_{1}\right)$

Atropine

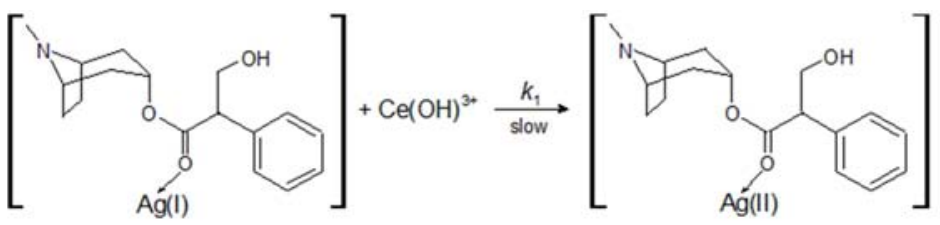

$\left(C_{1}\right)$

$\left(\mathrm{C}_{2}\right)+\mathrm{Ce}(\mathrm{OH})^{2+}$

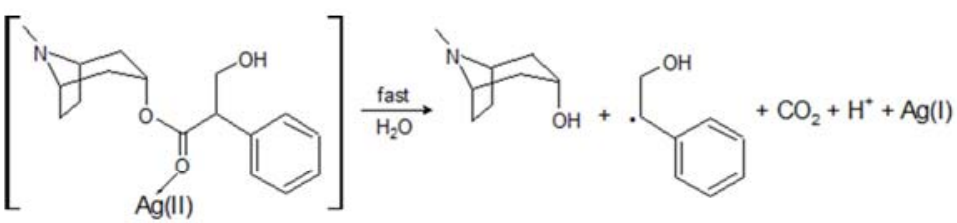

Scheme 2. An alternative oxidation mechanism of atropine by $\mathrm{Ce}(\mathrm{IV})$ in perchlorate solution.

The suggested mechanistic Schemes lead to the following rate law expression (see Appendix),

$$
\text { Rate }=\frac{k_{1} K_{\mathrm{OH}} K_{1}[\mathrm{Ce}(\mathrm{IV})][\mathrm{ATR}][\mathrm{Ag}(\mathrm{I})]}{\left[\mathrm{H}^{+}\right]\left(1+K_{1}[\mathrm{ATR}]\right)+K_{\mathrm{OH}}+K_{\mathrm{OH}} K_{1}[\mathrm{ATR}]}
$$

The rate law (9) is consistent with all the observed orders with respect to different species. Under pseudo-first order condition, the rate-law can be expressed by Eq. (10),

$$
\text { Rate }=\frac{-d[\mathrm{Ce}(\mathrm{IV})]}{d t}=k_{\mathrm{C}}[\mathrm{Ce}(\mathrm{IV})]
$$

Comparing Eqs. (9) and (10), the following relationship is obtained,

$$
k_{\mathrm{C}}=\frac{k_{1} K_{\mathrm{OH}} K_{1}[\mathrm{ATR}][\mathrm{Ag}(\mathrm{I})]}{\left[\mathrm{H}^{+}\right]\left(1+K_{1}[\mathrm{ATR}]\right)+K_{\mathrm{OH}}+K_{\mathrm{OH}} K_{1}[\mathrm{ATR}]}
$$

Rearrangement of the previous equation leads to the following equation,

$$
\frac{[\mathrm{Ag}(\mathrm{I})]}{k_{\mathrm{C}}}=\left(\frac{1}{k_{1} K_{1}}\right) \frac{1}{[\mathrm{ATR}]}+\frac{1}{k_{1}}+\left(\frac{1+K_{1}[\mathrm{ATR}]}{k_{1} K_{\mathrm{OH}} K_{1}[\mathrm{ATR}]}\right)\left[\mathrm{H}^{+}\right]
$$

Eq. (12) requires that the plots of $[\mathrm{Ag}(\mathrm{I})] / k_{\mathrm{C}}$ versus $1 /[\mathrm{ATR}]$ at constant $\left[\mathrm{H}^{+}\right]$, and $[\mathrm{Ag}(\mathrm{I})] / k_{\mathrm{C}}$ versus $\left[\mathrm{H}^{+}\right]$at constant [ATR] to be linear with positive intercepts and are found to be so as shown in figure 7 (a) and (b), respectively.

Activation parameters listed in table 2 may be discussed as follows. The observed large negative values of entropy of activation, $\Delta S^{\#}$, suggests that the reactants form an intermediate complex which are more ordered than the reactants, due to loss of degrees of freedom [38]. Also, the obtained values of $\Delta S^{\#}$ are within the range of radical reactions. On the other hand, the positive values of both $\Delta H^{f}$ and $\Delta G^{\neq}$indicate the endothermic formation of the intermediate complex and its non-spontaneity, respectively. 


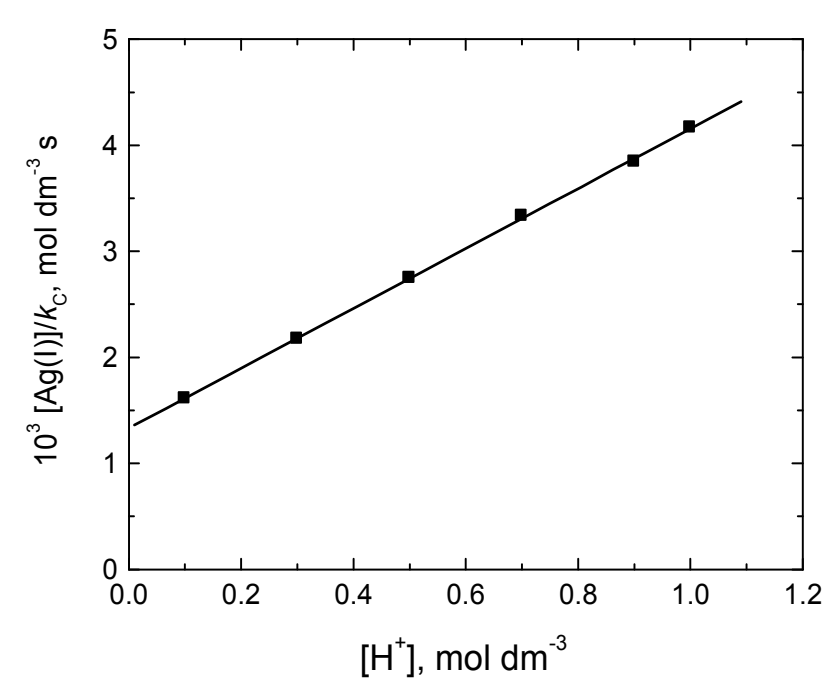

(a)

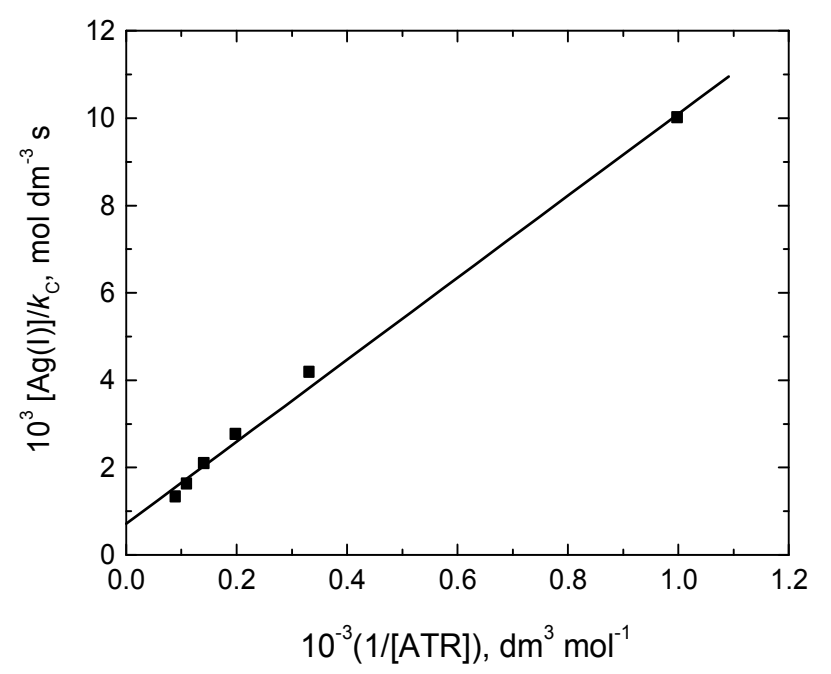

(b)

Figure 7. Verification of equation (12) in the silver(I)-catalyzed oxidation of atropine by $\mathrm{Ce}(\mathrm{IV})$ in perchlorate solutions. $[\mathrm{Ce}(\mathrm{IV})]=2.0 \times 10^{-4}$ and $\mathrm{I}=$ $1.0 \mathrm{~mol} \mathrm{dm} \mathrm{m}^{-3}$ at $25^{\circ} \mathrm{C}$.

\section{Conclusions}

The oxidation of atropine by cerium(IV) in perchlorate solutions did not take place without addition of silver(I) catalyst. The kinetically active species of cerium(IV) was found to be $\mathrm{Ce}(\mathrm{OH})^{3+}$. The oxidation products of atropine were identified as tropine, benzaldehyde, methanol and carbon dioxide. The mechanistic scheme for the catalyzed oxidation has been proposed. The activation parameters of the second order rate constant were calculated and the ratelaw expression associated with the reaction mechanism was derived.

\section{Appendix: Derivation of Rate-Law Expression}

According to the suggested mechanistic Schemes 1 and 2,

$$
\begin{gathered}
\text { Rate }=\frac{-d[\mathrm{Ce}(\mathrm{IV})]}{d t}=k_{1}\left[\mathrm{Ce}(\mathrm{OH})^{3+}\right]\left[\mathrm{C}_{1}\right] \\
K_{\mathrm{OH}}=\frac{\left[\mathrm{Ce}(\mathrm{OH})^{3+}\right]\left[\mathrm{H}^{+}\right]}{\left[\mathrm{Ce}^{4+}\right]},\left[\mathrm{Ce}(\mathrm{OH})^{3+}\right]=\frac{K_{\mathrm{OH}}\left[\mathrm{Ce}^{4+}\right]}{\left[\mathrm{H}^{+}\right]} \\
K_{1}=\frac{\left[\mathrm{C}_{1}\right]}{[\mathrm{ATR}][\mathrm{Ag}(\mathrm{I})]},\left[\mathrm{C}_{1}\right]=K_{1}[\mathrm{ATR}][\mathrm{Ag}(\mathrm{I})]
\end{gathered}
$$

Substituting Eqs. (14) and (15) into Eq. (13) yields,

$$
\text { Rate }=\frac{k_{1} K_{\mathrm{OH}} K_{1}\left[\mathrm{Ce}^{4+}\right][\mathrm{ATR}][\mathrm{Ag}(\mathrm{I})]}{\left[\mathrm{H}^{+}\right]}
$$

The total concentration of atropine is given by,

$$
[\mathrm{ATR}]_{\mathrm{T}}=[\mathrm{ATR}]_{\mathrm{F}}+\left[\mathrm{C}_{1}\right]
$$

where $[\mathrm{ATR}]_{\mathrm{T}}$ and $[\mathrm{ATR}]_{\mathrm{F}}$ stand for total and free concentrations of atropine, respectively.

Therefore,

$$
\begin{gathered}
{[\mathrm{ATR}]_{\mathrm{T}}=[\mathrm{ATR}]_{\mathrm{F}}+K_{1}[\mathrm{ATR}][\operatorname{Ag}(\mathrm{I})]=[\mathrm{ATR}]_{\mathrm{F}}\left(1+K_{1}[\mathrm{Ag}(\mathrm{I})]\right)} \\
{[\mathrm{ATR}]_{\mathrm{F}}=\frac{[\mathrm{ATR}]_{\mathrm{T}}}{1+K_{1}[\mathrm{Ag}(\mathrm{I})]}}
\end{gathered}
$$

Similarly,

$$
\begin{gathered}
{[\operatorname{Ag}(\mathrm{I})]_{\mathrm{T}}=[\operatorname{Ag}(\mathrm{I})]_{\mathrm{F}}+\left[\mathrm{C}_{1}\right]} \\
{[\operatorname{Ag}(\mathrm{I})]_{\mathrm{F}}=\frac{[\operatorname{Ag}(\mathrm{I})]_{\mathrm{T}}}{1+K_{\mathrm{l}}[\mathrm{ATR}]}}
\end{gathered}
$$

and

$$
\begin{gathered}
{[\mathrm{Ce}(\mathrm{IV})]_{\mathrm{T}}=\left[\mathrm{Ce}^{4+}\right]_{\mathrm{F}}+\left[\mathrm{Ce}(\mathrm{OH})^{3+}\right]=\left[\mathrm{Ce}^{4+}\right]_{\mathrm{F}}\left(1+\frac{K_{\mathrm{OH}}}{\left[\mathrm{H}^{+}\right]}\right)} \\
{\left[\mathrm{Ce}^{4+}\right]_{\mathrm{F}}=\frac{[\mathrm{Ce}(\mathrm{IV})]_{\mathrm{T}}}{1+\frac{K_{\mathrm{OH}}}{\left[\mathrm{H}^{+}\right]}}}
\end{gathered}
$$

Substituting Eqs. (19), (21) and (23) into Eq. (16) (and omitting ' $\mathrm{T}$ ' and ' $\mathrm{F}$ ' subscripts) gives,

$$
\text { Rate }=\frac{k_{1} K_{\mathrm{OH}} K_{1}[\mathrm{Ce}(\mathrm{IV})][\mathrm{ATR}][\mathrm{Ag}(\mathrm{I})]}{\left(\left[\mathrm{H}^{+}\right]+K_{\mathrm{OH}}\right)\left(1+K_{1}[\mathrm{Ag}(\mathrm{I})]\right)\left(1+K_{1}[\mathrm{ATR}]\right)}
$$

$$
\text { Rate }=\frac{k_{1} K_{\mathrm{OH}} K_{1}[\mathrm{Ce}(\mathrm{IV})][\mathrm{ATR}][\mathrm{Ag}(\mathrm{I})]}{\left(\left[\mathrm{H}^{+}\right]+K_{\mathrm{OH}}\right)\left(1+K_{1}[\mathrm{ATR}]+K_{1}[\operatorname{Ag}(\mathrm{I})]+K_{1}^{2}[\mathrm{ATR}][\operatorname{Ag}(\mathrm{I})]\right)}
$$

In view of the low concentration of $[\mathrm{Ag}(\mathrm{I})]$ used, the terms $K_{1}[\mathrm{Ag}(\mathrm{I})]$ and $K_{1}^{2}[\mathrm{ATR}][\mathrm{Ag}(\mathrm{I})]$ in the denominator of Eq. (25) can be neglected. Therefore, Eq. (25) becomes,

$$
\text { Rate }=\frac{k_{1} K_{\mathrm{OH}} K_{1}[\mathrm{Ce}(\mathrm{IV})][\mathrm{ATR}][\mathrm{Ag}(\mathrm{I})]}{\left[\mathrm{H}^{+}\right]\left(1+K_{1}[\mathrm{ATR}]\right)+K_{\mathrm{OH}}+K_{\mathrm{OH}} K_{1}[\mathrm{ATR}]}
$$

Under pseudo-first order condition, the rate-law can be expressed by Eq. (A15), 


$$
\text { Rate }=\frac{-d[\mathrm{Ce}(\mathrm{IV})]}{d t}=k_{\mathrm{C}}[\mathrm{Ce}(\mathrm{IV})]
$$

Comparing Eqs. (26) and (27),

$$
k_{\mathrm{C}}=\frac{k_{1} K_{\mathrm{OH}} K_{1}[\mathrm{ATR}][\mathrm{Ag}(\mathrm{l})]}{\left[\mathrm{H}^{+}\right]\left(1+K_{1}[\mathrm{ATR}]\right)+K_{\mathrm{OH}}+K_{\mathrm{OH}} K_{1}[\mathrm{ATR}]}
$$

and with rearrangement, the following equations are obtained,

$$
\frac{[\mathrm{Ag}(\mathrm{I})]}{k_{\mathrm{C}}}=\left(\frac{1}{k_{1} K_{1}}\right) \frac{1}{[\mathrm{ATR}]}+\frac{1}{k_{1}}+\left(\frac{1+K_{1}[\mathrm{ATR}]}{k_{1} K_{\mathrm{OH}} K_{1}[\mathrm{ATR}]}\right)\left[\mathrm{H}^{+}\right]
$$

\section{References}

[1] Bartholomew B A, Smith M J, Trudgill P W and Hopper D J (1996) Atropine metabolism by pseudomonas sp. Strain AT3: Evidence for nortropine as an intermediate in tropine breakdown and reactions leading to succinate. Appl. Environ. Microbiol., 62: 3245-3250.

[2] Brust J C M (2004) In Neurological aspects of substance aabuse, $2^{\text {nd }}$ (ed.) (Philadelphia: Elsevier) p. 310.

[3] Rörsch A, Berends F A, Bartlema C H, Stevens W F and Winsinck F (1971) The isolation and properties of Pseudomonas strains growing on atropine and producing an atropine esterase, Proc. K. Ned. Akad. Wet. Ser. C, 74:132147.

[4] Hassan RM, Alaraifi A, Fawzy A, Zaafarany IA, Khairou KS, Ikeda Y and Takagi HD (2010) Acid-catalyzed oxidation of some sulfated polysaccharides. Kinetics and mechanism of oxidation of kappa-carrageenan by cerium(IV) in aqueous perchlorate solutions. J. Mol. Cat. A, 332: 138-144.

[5] Fawzy A (2016) Oxidation of alginate and pectate biopolymers by cerium(IV) in perchloric and sulfuric acid solutions: A comparative kinetic and mechanistic study, Carbohydr. Polym., 138: 356-364.

[6] Fawzy A (2016) Kinetic and mechanistic aspects of oxidation of aminotriazole formamidine by cerium(IV) in aqueous perchloric and sulfuric acid solutions: a comparative study. J. Solution Chem., 45: 46-264.

[7] Fawzy A, Hassan R M, Althagafi I and Morad M (2016) Cerium(IV) oxidation of sulfated polysaccharides in aqueous perchlorate solutions. A Kinetic and mechanistic approach. Adv. Mater. Lett., 7, 122-128.

[8] Fawzy A, Zaafarany I A, Tirkistani F A, Al-Benayan A and Aljiffrey F A (2016) Kinetics and mechanistic study of oxidation of pyridine derivative by cerium(IV) in aqueous perchloric acid, Am. J. Phys. Chem., 5: 10-16.

[9] Richardson W H (1965) Oxidation of organic chemistry, In K B Wiberg (ed.) (Academic Press: London) p. 244.

[10] Adari KK, Nowduri A, Parvataneni V (2008) Kinetics and mechanism of oxidation of L-cystine by cerium(IV) in sulphuric acid medium. Acta Chim. Slov., 55: 425-429.

[11] Sumathi T, Shanmugasundaram P and Chandramohan G 2013 A kinetic and mechanistic study on the silver(I) catalyzed oxidation of L-Serine by cerium(IV) in sulfuric acid medium. J. Saudi Chem. Soc., 17: 227-233.
[12] Thabaj KA, Chimatadar SA, Nandibewoor ST (2006) Mechanistic study of oxidation of palladium(II) by cerium(IV) in aqueous acid. Transition Met. Chem., 31: 186-193.

[13] Datt N, Nagori RR, Mehrotra RN (1986) Kinetics and mechanisms of oxidations by metal ions. Part VI. Oxidation of $\alpha$-hydroxy acids by cerium(IV) in aqueous nitric acid. Can. J. Chem., 64: 19-23.

[14] McCurdy, Jr W H and Guilbault G G 1960 Catalysts for cerium(IV) oxidimetry: determination of mixtures of mercury(I) and mercury(II). Anal. Chem., 32: 647-650.

[15] Mishra S K and Gupta Y K (1970) Kinetics of oxidation of antimony(III) by cerium(IV) in media containing perchloric acid. J. Chem. Soc. A, 260-264.

[16] Yadav MB, Derva V, Rani A (2009) Kinetics and mechanism of uncatalyzed and silver(I) catalyzed oxidation of lysine by cerium(IV) in acid perchlorate medium. J. Indian Chem. Soc., 86: 600-604.

[17] Mathur S, Yadav MB, Devra V (2013) Kinetics and mechanism of uncatalyzed and $\operatorname{Ag}(\mathrm{I})$ catalyzed oxidation of hydroxylysine by cerium(IV) in acid medium. J. Phys. Chem. Biophys., 3:5-12; Mathur S, Yadav MB, Devra V (2015) Kinetics and mechanism of uncatalyzed and $\operatorname{Ag}(\mathrm{I})$ catalyzed oxidation of serine by cerium(IV) in acid medium. Int. J. Res. Phys. Chem., 5: 1-6.

[18] Fawzy A (2014) Influence of copper(II) catalyst on the oxidation of L-histidine by platinum(IV) in alkaline medium: a kinetic and mechanistic study, Transition Met. Chem., 39 567-576.

[19] Fawzy A (2015) Kinetics and mechanistic approach to the oxidative behavior of biological anticancer platinum(IV) complex towards L-asparagine in acid medium and the effect of copper(II) catalyst, Int. J. Chem. Kinet., 47: 1-12.

[20] Fawzy A and Asghar B H 2015 Kinetics and mechanism of uncatalyzed and silver(I)-catalyzed oxidation of L-histidine by hexachloroplatinate(IV) in acid medium, Transition Met. Chem., 40: 287-295.

[21] Kirthi S. Byadagi, Rajeshwari V. Hosahalli, Sharanappa T. Nandibewoor, and Shivamurti A. Chimatadar (2012) Oxidation of a anticholinergic drug atropine sulfate monohydrate by alkaline copper(III) periodate complex: a kinetic and mechanistic study. Z. Phys. Chem., 226: 233-249.

[22] Byadagi K S, Nandibewoor S T and Chimatadar S A (2013) Catalytic activity of ruthenium(III) on the oxidation of an anticholinergic drug-atropine sulfate monohydrate by copper(III) periodate complex in aqueous alkaline medium decarboxylation and free radical mechanism. Acta Chim. Slov., 60: 617-627.

[23] Meti M, Nandibewoor S and Chimatadar S (2014) Spectroscopic investigation and oxidation of the anticholinergic drug atropine sulfate monohydrate by hexacyanoferrate(III) in aqueous alkaline media: a mechanistic approach, Turk. J. Chem., 38: 477-487.

[24] Abdullah S, Al-Ghreizat S K and Abdel-Halim H M (2015) Kinetics of oxidation of atropine by alkaline $\mathrm{KMnO}_{4}$ in aqueous solutions. Asian J. Chem., 27: 3877-3882.

[25] Do Pham D D, Kelso G F, Yang Y and Hearn M T W (2014) Studies on the oxidative N-demethylation of atropine, thebaine and oxycodone using a FeIII-TAML catalyst, Green Chem., 16: 1399-1405. 
[26] Hardwick TJ, Robertson E (1951) Ionic species in ceric perchlorate solutions. Can. J. Chem., 29: 818-828.

[27] Furniss B S, Hannaford A J, Smith W G and Tatchell A R (2004) In Vogel's textbook of practical organic chemistry, $5^{\text {th }}$ (ed.) (Pearson Education Ltd).

[28] Vogel A I (1973) In Text book of practical organic chemistry, $3^{\text {rd }}$ (ed.) (London: Longman) p. 332.

[29] Feigl F (1975) Spot tests in organic analysis, p. 195, Elsevier, New York.

[30] Sherill MS, King CB, Spooner RC (1943) The oxidation potential of cerous-ceric perchlorates. J. Am. Chem. Soc., 65: 170-179.

[31] Heidt LJ, Smith ME (1948) Quantum yields of the photochemical reduction of ceric ions by water and evidence for the dimerization of ceric ions. J. Am. Chem. Soc., 70: 2476-2481.

[32] King EL, Pandow ML (1952) The spectra of cerium(IV) in perchloric acid. Evidence for polymeric species. J. Am. Chem. Soc., 74: 1966-1969.
[33] Offner HG, Skoog DA (1966) Hydrolysis constant of quadrivalent cerium from spectrometric measurements. Anal. Chem., 38: 1520-1521.

[34] Leal JM, Domingo PL, Garcla B, Ibeas S (1993) Alkali metal ion catalysis of the oxidation of L-ascorbic acid by hexacyanoferrate(III) in strongly acidic media. J. Chem. Soc. Faraday Trans., 89: 3571-3577.

[35] Frost AA, Person RG (1973) Kinetics and mechanism, p. 147, Wiley Eastern, New Delhi.

[36] Amis ES (1966) Solvent effect on reaction rates and mechanism, p. 28, Academic Press, New York.

[37] Michaelis L, Menten ML (1913) The kinetics of invertase action. Biochem. Z., 49: 333-369.

[38] Weissberger A (1974) In Investigation of rates and mechanism of reactions in techniques of chemistry, (New York: John Wiley \& Sons), p. 421. 